\title{
The Deviation of Rural Teachers' Self Cognition and the Implementation of Teaching Decision Making in Guangdong
}

\author{
Li Jingjing \\ Lingnan Normal University.Education Science College.Department of Education, 524048
}

Keywords: Rural Teachers in Guangdong province; self-cognition; teaching strategy; teaching implementation

\begin{abstract}
: the key to the development of education in rural teachers, rural teachers self professional development stage of professional development of the existing concept is backward, weak awareness of professional development, professional development, professional development of weak knowledge of limited resources and limited ability of professional development, to promote teachers professional development must establish self consciousness and self Strengthening Occupation identity, professional development establishment of self professional development planning, autonomous learning and self reflection, education and teaching research.
\end{abstract}

\section{Introduction}

In recent years, education reform has been carried out all over the world. The key to the success of education reform lies in teachers. Only when teachers' professional level is continuously improved can high quality education be made. Therefore, the professional development of teachers has become the focus of attention all over the world. Since the reform and opening up, China's rapid economic development, city level increased significantly, but it is undeniable that China is still an agricultural country, according to the National Bureau of statistics of the sixth national census bulletin shows that 31 mainland provinces, autonomous regions and municipalities directly under the central government and servicemen of the population, living in a rural population accounted for $50.32 \%$. To build a well-off society in an all-round way and realize the modernization of education, rural education must be vigorously developed. Influenced by many factors, such as unbalanced urban and rural development, inconvenient transportation geography conditions and poor school running conditions, the current rural teachers in Guangdong province are facing the problems of poor professional quality and lack of professional ability, which restrict the development of rural education. The development of rural education is an important event in the present age and in the future. Teachers are the key to the development of rural education. Therefore, strengthening the construction of rural teachers and improving the professional development level of rural teachers has become the top priority of the reform and development of China's education.

The professional development view of traditional teachers in Guangdong believes that teachers are constantly growing under the influence of external forces, emphasizing the role of external measures such as training and policy guidance. The professional development view of modern teachers believes that the essence of teacher's professional development is the autonomy of development. Teachers are not only the object of professional development, but also the master of professional development, emphasizing that teachers should seek the source and power of self growth from teachers' practical activities. The external drive and spontaneous state cannot promote teachers' professional development fundamentally, only arouse teachers' autonomy, so that teachers become active participants in their own development, driven and spontaneous state into the internal drive and the conscious self development from the outside, in order to fundamentally promote the professional development of teachers. 


\section{The Problems of Rural Teachers' Self Professional Development}

Educational philosophy is the ideological and spiritual pursuit of guiding educational behavior. It is in the highest position in the professional development of teachers, and determines other elements of the professional development of teachers. Correct educational concept is the leading condition for teachers to realize their professional development. Teachers' role in the new era should be a facilitator, cooperation and guide positioning in student learning, but many teachers in rural areas still hold the idea of teachers' occupation tenure, only the teacher's occupation as a means of livelihood, the teachers as a lifelong career, the lack of firm belief in education, lack of education ideal. The power loss of professional development.

Teachers' professional development needs certain economic conditions. Compared with urban schools, rural schools offer limited training opportunities for teachers' professional development. The low investment in rural education leads to the backwardness of the software and hardware conditions of rural schools, which makes the rural teachers lack the external conditions for professional development, and the limited resources of teachers' independent professional development. The imbalance between teachers and students in rural schools, the limited resources of teachers, some teachers teaching more than one grade, many courses, not only will increase the burden on teachers, but also make them lack of clear understanding of their own professional development direction. At the same time, the evaluation mechanism of examination makes many teachers use the only spare time to guide students' homework, improve students' academic achievement, and lead to limited time for their professional development.

Students, classroom and teaching are the source of teachers' professional development. Teachers' professional development must be based on students' practice, classroom practice and teaching practice. Rural teachers' professional development ability is deficient, and classroom teaching practice activities are mostly based on past experience. They are random and accidental. Rural teachers seldom study teaching activities actively and systematically from the perspective of specialty. They lack overall consciousness and research consciousness. Some teachers are aware of the importance of research to promote professional development, but because there is no systematic research education or related training, lack of training environment and excellent guide, do not know how to carry out effective research. More rural teachers stay in the single stage of reading textbooks and preparing lessons more frequently, and their professional development ability is limited.

\section{The Path of Rural Teachers' Self Professional Development}

Mr. Cai Yuanpei thinks that a man can be independent by himself first, and then he can be a man. Ushinski, a famous Russian educator, said: "in teaching, everything should be based on the personality of educators. Any statute and program, any human management organization, no matter how sophisticated they say, can not replace the role of personality in education. Without the teacher's direct influence on the students and the depth of the students' character, true education is impossible." This shows how important the teacher's personality is to the students. The teacher studious spirit, hard working spirit, optimistic is upward attitude, generous and open-minded style directly affect the students. The teacher is a dedication to the cause, it not only affects the students' good or bad, but also affect the students' future, more important impact on the future of the motherland.

The teacher's love for students is a very important means of education. As a teacher, if you want to make students respect yourself, first of all, you should respect your own personality, and we have such an adage: "people must respect themselves, and then respect them."'. A qualified teacher must have strong ability of self management, with a strong sense of collectivism, to keep their reputation and collective work together, something the effectiveness for a person is of little importance, but the impact of the quality of students is profound. I think we should do it:

we should use emotion to grasp students and establish good relationship between teachers and 
students. Any teacher in teaching, only with the students to establish a good teacher-student relationship, in order to enable students to listen carefully, study dependably, in order to better grasp the students. This requires teachers to "emotional input", and its "input" must be based on Teachers' enthusiasm, kindness and kindness, put emotion in teaching, create a lively and pleasant learning atmosphere for students. Teachers use emotion, students get along well with each other, understand the different personalities and hobbies of different students, use different ways to find the students to talk, talk about the heart, so that students feel the teacher's kindness from the psychological. In education and teaching, teachers take care of students' attitude, patience and meticulous counseling, but also to their own quality and morality to influence students, so that the usual establishment of intimacy and trust emotion, can be communicated and developed in learning.

To love, respect and sincere love for students is a good psychological quality of teachers, and this good quality of the heart requires us to keep forging ahead, constantly learning advanced scientific and cultural knowledge, and constantly improve their education and teaching level and ability. Naturally, it will allow us to devote ourselves to our work and work with full emotion and energy.

we should set an example to promote the unity of students' words and deeds. People often say: "teachers without bars, everywhere is a model."'". School is the place where every student lives and studies. The way and means of school education has great influence on students. Teachers of Ideological and moral education of students is the responsibility of every teacher, teachers should establish the teachers, teaching ideas, put words together, and teach only set an example, to make teachers' words play a greater role, only teachers, to enable students from the image of teachers feel learning morality is trusted, willing to actively contribute to the unification of students' behavior. Only by making students active, teachers can have more time and energy to engage in teaching research and teaching work.

Love students, respect students, care for students, help students, willing to contribute, so that the relationship between teachers and students naturally harmonious, will also feel that their work is meaningful, but also happy, will let themselves actively to better work.

we must constantly improve their self-cultivation, will live, work. "High school teacher, highly for fan". Teachers are professionals who fulfill the responsibilities of education and teaching, undertake teaching and educating people, train builders and successors of socialist cause, and improve the quality of the nation. Teachers should be loyal to the people's education. Teacher's work is a special career of direct education, and its words and deeds have great influence on students' growth. The level of students' academic knowledge is largely restricted by the teacher's knowledge level. Teacher accomplishment can not be achieved overnight, it requires us to continue to learn advanced scientific and cultural knowledge, education as a career to do, not just to support the family career.

Education and teaching activities are the bilateral activities of teachers and students. The object of teacher education is living people. Therefore, teachers should make students as the main body in teaching, and provide every student with the educational conditions suitable for their potential development and personality development. Therefore, as a teacher, do not put to the dignity of the shelf, we should be fully aware of yourself, give yourself an accurate positioning, and students learning together people. Correct understanding of themselves, will accept themselves, in order to accept the reality of their own situation, not proud of their own merits, nor because of their own shortcomings and inferiority. With this kind of peaceful state of mind, you can release the greatest potential to participate in teaching and research, with full energy into teaching, with full enthusiasm to infect students, so that both themselves and students can become happy learning.

First of all, correct attitude. Don't always regard teachers as a special occupation, always think of the good treatment and social status. Arrange your daily work and life, and prioritize things. It is not easy for an individual to evaluate himself objectively, but it is impossible for him to evaluate himself objectively, and he can do it immediately. He needs the experience of life and baptism of years. But we can not sit still, to be good at listening to others in their opinions, suggestions and criticisms, there must be from mind, find out their advantages and shortcomings, and objective analysis. 
Secondly, teachers should have strong physique. Only strong physique, can better serve education. We often say that the body is the capital of revolution. Without a strong body, education can not be better served. Therefore, teachers should actively use the surrounding equipment for use, exercise their own body, so that their body is always healthy, so that their body is always strong.

Thirdly, we should arrange our education and teaching scientifically and play the role of media resources. Education and teaching work is a complex system, paying attention to scientific work. The preparation before class must be scientific and orderly, the implementation of the classroom must be maximized, and the supervision after class must be relaxed. At the same time, we should make full use of media resources. Teachers, students, teaching materials, media and so on are all media resources, and teachers and students are the most important resources, must play well. For example, training cadres, and play class cadres management level and leading role. Not only can save time, but also can improve the efficiency of education and teaching.

\section{Summary}

Teachers should constantly absorb new knowledge and improve their quality. One minute on the stage takes ten years. In the era of knowledge constantly updated, teachers should foster the thought of lifelong learning, into the new era of science and technology culture, literature and art should be more in inheriting the essence of traditional culture at the same time, only the teacher culture to keep pace with the times, can provide may promote the healthy development of students. In short, teachers should correct their mentality, fully understand themselves, strong physique, improve literacy, in order to promote the healthy development of students.

\section{References}

[1] Lv, Z., Halawani, A., Feng, S., Li, H., \& Réhman, S. U. (2014). Multimodal hand and foot gesture interaction for handheld devices. ACM Transactions on Multimedia Computing, Communications, and Applications (TOMM), 11(1s), 10.

[2] Yizheng Chen, Fujian Tang, Yi Bao, Yan Tang, *Genda Chen. A Fe-C coated long period fiber grating sensor for corrosion induced mass loss measurement. Optics letters, 41(2016), pp. 2306-2309.

[3] Yang Du, Yizheng Chen, Yiyang Zhuang, Chen Zhu, Fujian Tang, *Jie Huang. Probing Nanostrain via a Mechanically Designed Optical Fiber Interferometer. IEEE Photonics Technology Letters, 29(2017), pp. 1348-1351.

[4] Weisen Pan, Shizhan Chen, Zhiyong Feng. Automatic Clustering of Social Tag using Community Detection. Applied Mathematics \& Information Sciences, 2013, 7(2): 675-681.

[5] Yingyue Zhang, Qi Li, William J. Welsh, Prabhas V. Moghe, and Kathryn E. Uhrich, Micellar and Structural Stability of Nanoscale Amphiphilic Polymers: Implications for Anti-atherosclerotic Bioactivity, Biomaterials, 2016, 84, 230-240. 